\title{
An improved respiratory system for curarized rats*
}

\author{
CLAUDE J. GAEBELEIN $\dagger$ and JAMES L. HOWARD \\ Department of Psychiatry and the Biological Sciences Research Center of the Child Development Institute \\ University of North Carolina, Chapel Hill, North Carolina 27514
}

\begin{abstract}
A respiratory system is described in which peak expired $\mathrm{CO}_{2}$ is continuously monitored from curarized rats. Another alteration from previous systems is that an endotracheal tube is used to minimize dead air space. The adequacy of the system was tested by maintaining curarized rats at one level of peak expired $\mathrm{CO}_{2}$ for varying periods of time and by keeping rats at different peak expired $\mathrm{CO}_{2}$ levels for a fixed period of time. Results of blood gas analyses indicated that values obtained with this system are similar to values in noncurarized rats, and that manipulation of expired $\mathrm{CO}_{2}$ is an effective means of altering blood gas values.
\end{abstract}

Following the recent difficulties in replicating the earlier demonstrations of instrumental autonomic conditioning in the curarized rat (Miller \& Dworkin, 1974), several studies have shown that respiratory parameters used previously with paralyzed rats are inadequate (Brener, Eissenberg, \& Middaugh, 1974; Hahn, 1972), and it has been suggested that moderate to severe respiratory insufficiency may lead to a cardiovascular system insensitive to reinforcement contingencies (Howard, Galosy, Gaebelein, \& Obrist, 1974). The present paper describes a respiratory system that results in more normal blood gas tensions than have been previously reported in paralyzed rats (see Hahn, 1972, for review). The prominent improvements include use of an endotrachael tube (ET), rather than a face mask, to reduce dead air space and to ensure delivery of air to the lungs, and use of an expired gas analyzer to monitor peak expired $\mathrm{CO}_{2}$ on a breath-by-breath basis. This latter feature of the system permits continuous adjustments of the respirator to maintain optimal respiratory parameters, and precludes the necessity of multiple blood-gas determinations during an experimental session which may not only disturb the animal but also may have deleterious cardiovascular effects, e.g., by reducing blood volume.

\section{RESPIRATORY SYSTEM}

Major equipment used to construct the respiratory system consisted of a Beckman medical gas analyzer (Model LB-1), a modified Harvard rodent respirator (Model 681) (described by Gaebelein, Howard, \& Hutcheson, 1974), a Statham pressure transducer (Model P-233), a 20-liter flask, and assorted Y connectors and tubing. All measures were calibrated and recorded on a Beckman dynograph.

The respiratory system is depicted in Fig. 1. Air is

* This investigation was supported in part by Research Grant MH-07995, NIH, and Institutional Grant HE-03110, NICND, USPHS.

+Requests for reprints should be sent to Claude J. Gaebelein. Department of Psychiatry, University of North Carolina, School of Medicine, Chapel Hill, North Carolina 27514 delivered to the animal through the inspiration tubing, the $\mathrm{Y}$ connector, and ET. During the expiratory phase of the cycle, air passes through the $\mathrm{Y}$ connectors, expiratory tubing, $\mathrm{CO}_{2}$ monitor, a valve on the respirator, and is evacuated to the room by the $\mathrm{CO}_{2}$ sample pump. The large vented flash (venting done with a 23-ga needle) is used to damp the momentary pressure variations in the system. The negative pressure exerted by the pump was used to compensate for the resistance in the expiratory circuit caused by the $\mathrm{CO}_{2}$ monitor and was adjusted to produce an end-tidal expiratory pressure of $0 \mathrm{~mm} \mathrm{H} \mathrm{H}_{2} \mathrm{O}$ as measured by the pressure transducer.

\section{ENDOTRACHAEL TUBE}

The ET was adapted from Paleček (1969). It was constructed from an 8-cm length of polyethylene tubing (PE 240, Clay Adams), which was inserted into a $1 . \mathrm{cm}$ length of larger tubing (PE 350, Clay Adams); the larger tubing was connected to a male Luer-Lok fitting. To increase the rigidity of the ET during intubation, a plunger from a microsyringe was cut to be $0.5 \mathrm{~cm}$ longer than the ET and was covered to its tip with a piece of plastic tubing small enough to fit inside the ET (PE 120, Clay Adams). A tongue depressor was made from a $1.0-\mathrm{mm}$-thick piece of copper about $3 \mathrm{~cm}$ long and

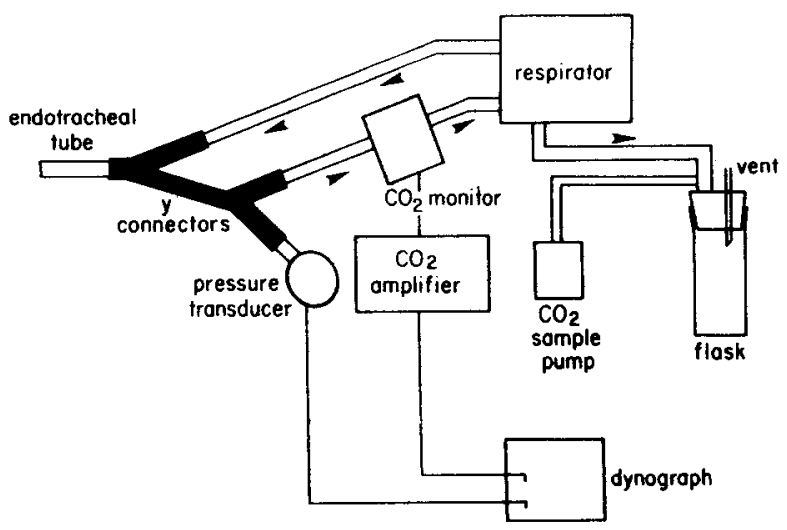

Fig. 1. Diagram of respiratory system, not to scale. Arrows indicate direction of air flow. 
Table 1

Effects of Duration of Curarization and Level of Expired $\mathrm{CO}_{2}$ on Blood Gas Tensions

\begin{tabular}{lccccc}
$\begin{array}{c}\text { Drug } \\
\text { Condition }\end{array}$ & $\begin{array}{c}\text { Elapsed } \\
\text { Time } \\
\text { (Min) }\end{array}$ & $\begin{array}{c}\text { Expired } \\
\mathrm{CO}_{2} \\
\text { (Percent) }\end{array}$ & $\begin{array}{c}\text { Blood } \\
\mathrm{pCO}_{2}\end{array}$ & $\begin{array}{c}\mathrm{Blood} \\
\mathrm{pO} / \mathrm{Hg}\end{array}$ \\
$(\mathrm{mm} / \mathrm{Hg})$ & $\begin{array}{c}\mathrm{Blood} \\
\mathrm{pH}\end{array}$ \\
\hline Control & & & 36.3 & 89.4 & 7.42 \\
Curare & 30 & 5.0 & 39.7 & 68.0 & 7.38 \\
Curare & 60 & 5.0 & 36.3 & $55.6^{*}$ & 7.41 \\
Curare & 90 & 5.0 & 35.7 & $55.6^{*}$ & 7.41 \\
Curare & 90 & $4.8-5.0$ & $31.4^{* *}$ & 57.6 & $7.46^{* *}$ \\
Curare & 90 & $5.2-5.4$ & $39.4^{* *}, \dagger 47.4 \dagger$ & $7.38 \dagger$ \\
\hline
\end{tabular}

${ }^{*}$ Differed from control value at $<.01$, two-tailed $t$ tests.

**Differed from 90-min, 5\% expired $\mathrm{CO}_{2}$ group values at $<.05$, two-tailed $t$ tests.

tDiffered from $90-\mathrm{min}, 4.8 \%-5.0 \%$ expired $\mathrm{CO}_{2}$ group values at $<.05$, two-tailed $t$ tests.

narrow enough to fit between the teeth of the rat's lower jaw. One end of the depressor was tapered and arched to be slightly greater than the contour of the rat jaw. The other end was cut square and was clamped in the teeth of a hemostat at a right angle to the shaft. A support for the upper jaw was made by bending one end of a heavy wire to form a $U$, and attaching the other end to a ring stand with a clamp. Visualization of the animal's throat was facilitated with a head parabolic reflector worn by the $\mathrm{E}$.

Intubation was accomplished following the placement of the rat in an ether-filled jar until lightly anesthetized. The animal's head was then suspended from the $U$ of the wire by its upper front incisors. The tongue depressor was inserted and extended along the roof of the mouth to the extreme caudal region and then rotated ventrally to depress the epiglottis. This procedure effectively exposed the larynx. The ET and the smaller reinforcing tube were then inserted so that the smaller tube entered the trachea, at which point the larynx spasmed. The ET was then extended over the smaller tube until it entered the trachea and was situated about $1 \mathrm{~cm}$ caudal to the larynx. The smaller tube was withdrawn, and the ET attached to the respiratory apparatus.

\section{EXPERIMENT}

\section{Method}

The adequacy of this system was tested by maintaining rats at several levels of peak expired $\mathrm{CO}_{2}$ for varying periods of time (see Table 1) while the animals were immobilized with an infusion of succinylcholine chloride (SC) through a catheter in the right jugular vein. An average respiratory rate of 72 breaths/min with an $\mathrm{I}: \mathrm{E}$ ratio of $1: 2$ at $15 \mathrm{~cm} . \mathrm{H}_{2} \mathrm{O}$ peak inspiratory pressure was used. Core temperature was maintained at $37^{\circ} \mathrm{C}$ with a heating pad. Afterwards, $0.5 \mathrm{cc}$ of blood was drawn from a catheter in the left carotid artery and analyzed with an Instrumentation Laboratories (Model 113) blood gas analyzer to determine $\mathrm{pCO}_{2}$ and $\mathrm{pO}_{2}$ tensions and $\mathrm{pH}$. To obtain control values, blood was sampled from other rats immediately following the arterial catheterization under ether anesthesia.

\section{Results}

Average values for $\mathrm{pCO}_{2}, \mathrm{pO}_{2}$, and $\mathrm{pH}$ are presented in Table 1. Differences among these values, as assessed by $\mathrm{t}$ tests, indicated that $\mathrm{pCO}_{2}$ and $\mathrm{pH}$ levels were similar to control values up to $90 \mathrm{~min}$ under SC with peak expired $\mathrm{CO}_{2}$ at $5 \%$. Levels of $\mathrm{pO}_{2}$, however, declined from control values after $30 \mathrm{~min}$ of immobilization. This latter effect may have been due to certain side effects of the drug, such as a progressive decrease in lung compliance throughout the session or to the release of histamine, and may be remedied by gradually increasing the peak inspiratory pressure during the session (Brener, Eissenberg, \& Middaugh, 1974), by pretreatment with an antihistamine (Howard, Galosy, Gaebelein, \& Obrist, 1974), and/or by adding $\mathrm{O}_{2}$ to the inspired air.

Comparison of blood gas levels $90 \mathrm{~min}$ after curarization at different peak expired $\mathrm{CO}_{2}$ values suggested that altering peak expired $\mathrm{CO}_{2}$ was an effective means of changing blood gas levels. That is, increasing or decreasing expired $\mathrm{CO}_{2}$ from $5 \%$ reliably shifted $\mathrm{pCO}_{2}$ in the appropriate direction. Less sensitivity was observed with $\mathrm{pO}_{2}$ in that values obtained at peak expired $\mathrm{CO}_{2}$ levels above and below $5 \%$ differed from each other but not from the value seen at 5\%. Alterations in $\mathrm{pH}$ showed a similar trend, with extreme values differing from each other and the $\mathrm{pH}$ values at $5 \%$ being less than those observed at the expired $\mathrm{CO}_{2}$ level of less than $5 \%$.

\section{DISCUSSION}

Blood gas values obtained in this study more closely resemble physiologically normal levels than results reported by other investigators (e.g., DiCara, 1970; Hahn, 1972). This superiority is achieved through modifications in equipment, technique, and recording. For example, the use of a small negative pressure during the expiratory phase of the ventilatory cycle enables the adjustment of end-tidal pressure to $0 \mathrm{~cm} \mathrm{H}_{2} \mathrm{O}$ and ensures a complete exhalation. In addition, the use of an endotrachael tube minimizes dead space and ensures delivery of air to the lungs of the animal. However, care should be taken with this device. For example, the distal end should not be cut too sharply, to minimize discomfort and to avoid puncturing the trachea. In addition, the irritation to the trachea produced by the tube can lead to mucous secretion. We have found, however, that pretreatment of the animal with an antihistamine (Marezine, $2 \mathrm{mg} / \mathrm{kg}$ ) effectively reduces these secretions. Finally, large changes in pressure might accompany small changes in respiration settings, pointing out the necessity of monitoring expiratory pressures constantly, and making necessary adjustments. Regarding recording, it is important to note that the respiratory rate of these animals was greater than that 
permitted by the time constant of the gas analyzer, resulting in an expired $\mathrm{CO}_{2}$ output that did not return to $0 \%$ at the end of each expiration. Although the expired gas values are thus not directly comparable to those in which an end expiratory level of $0 \%$ was observed (Howard, Turner, Gaebelein, \& Galosy, 1973), maintaining a peak expiratory $\mathrm{CO}_{2}$ of $5 \%$ resulted in satisfactory blood gas levels in both cases. Thus, this system would appear to be useful over a wide range of respiratory rates for a variety of small animals.

The application of this system seems relevant in studies of autonomic conditioning, particularly since proper ventilation of the curarized animal may, in part, lead to the resolution of the recently reported difficulty of replicating earlier reports dealing with successful instrumental conditioning of visceral responses (Miller \& Dworkin, 1974).

\section{REFERENCES}

Brener, J., Eissenberg, E., \& Middaugh, S. Respiratory and somatomotor factors associated with operant conditioning of cardiovascular responses in curarized rats. In P. A. Obrist, A. H. Black, J. Brener, and L. V. DiCara (Eds.), Cardiovascular psychophysiology: Current issues in response mechanisms, biofeedback, and methodology. Chicago: Aldine Atherton, 1974 , in press.

DiCara, T. V. Analysis of arterial blood gases in the curarized, artificially respirated rat. Behavior Research Methods \& Instrumentation, 1970, 2, 67-70.

Gaebelein, C. J., How ard, J. L., \& Hutcheson, J. S. An inexpensive modification of a rodent respirator to achieve variable inspiration:inspiration ratios. Behavior Research Methods \& Instrumentation, 1974, in press.

Hahn, W. W. Physiological state of the curarized rat: Implications for the learned control of autonomic responses. Paper presented at the 12 th Annual Meeting of the Society for Psychophysiological Research, Boston, 1972.

Howard, J. L., Galosy, R. A. Gaebelein, C. J., \& Obrist, P. A. Some problems in the use of neuromuscular blockage. In P. A. Obrist, A. H. Black, J. Brener, and L. V. DiCara (Eds.), Cardiovascular psychophysiology: Current issues in response mechanisms, biofeedback, and methodology. Chicago: Aldine-Atherton, 1974 , in press.

Howard, J. L., Turner, M. A., Gaebelein, C. J., \& Galosy, R. A. Operant conditioning of heart rate in curarized cats. Paper presented at the 13th Annual Meeting of the Society for Psychophysiological Research, Galveston, 1973.

Miller, N. E., \& Dworkin, B. R. Visceral learning: Recent difficulties with curarized rats and significant problems for human research. Cardiovascular psychophysiology: Current issues in response mechanisms, biofeedback, and methodology. Chicago: Aldine-A therton, 1974, in press.

Paleček, F. Measurement of ventilatory mechanisms in the rat. Journal of Applied Physiology, 1969, 27, 149-156.

(Received for publication January 18, 1974; revision received April 1,1974 .) 